\title{
I
}

\section{ENSINO DE CIÊNCIAS NO CONTEXTO AMAZÔNICO: REFLETINDO SOBRE A EDUCAÇÃO EM CIÊNCIAS*}

\author{
Andria Raiane Coelho Campos ${ }^{1}$ \\ Ednilson Sergio Ramalho de Souza ${ }^{2}$
}

\section{Introdução}

Os indivíduos adquirem conhecimentos em todas as fases da vida. Mas é no ambiente escolar que lhes são apresentadas experiências de aprendizagem mais significativas, uma vez que, é nesse espaço que se começa a construir o senso de cidadania, sendo esse a primeira etapa de vida em sociedade fora do convívio familiar.

O conhecimento pode ser definido como a aquisição de uma noção nova ou original, sobre um fato ou fenômeno qualquer. Portanto, origina-se nas experiências que se acumulam na vida cotidiana, nos relacionamentos interpessoais, nas leituras de livros e na consulta a fontes diversas (ALYRIO, 2009). A produção de conhecimento ocorre a partir de três razões principais: questionamentos, necessidade, curiosidades (SANTOS; KIENEN; CASTIÑEIRA, 2015).

A relação do sujeito com a realidade em que vive influencia na construção do conhecimento científico. A escola como um espaço "facilitador" para a aprendizagem e domínio de conteúdos pode auxiliar no desenvolvimento de habilidades necessárias à vida em sociedade, tais como o senso crítico, questionador - tão necessário para o desenvolvi-

\footnotetext{
*DOI - 10.29388/978-65-86678-45-1-0-f.27-40

${ }^{1}$ Mestranda do Programa de Pós-Graduação em Educação - Universidade Federal do Oeste do Pará - UFOPA. Linha de Pesquisa: Conhecimento e formação na educação escolar, sob a orientação do Prof. Dr. Ednilson Sergio Ramalho de Souza. E-mail: andriacoelho@gmail.com.

${ }^{2}$ Doutor em Educação em Ciências e Matemática pela Universidade Federal do Mato Grosso/ Rede Amazônica de Educação em Ciências e Matemática (UFMT/REAMEC). Docente do Programa de Pós-graduação em Educação da Universidade Federal do Oeste do Pará-UFOPA. Líder do GEPEMM (Grupo de Estudos e Pesquisas Educacionais em Modelagem Matemática/ UFOPA). E-mail: ednilson.souza@ufopa.edu.br.
} 
mento da Ciência- para que através desses possa compreender a realidade em está inserido.

A educação é um fenômeno muito amplo e próprio do ser humano que segundo Dermeval Saviani, diz respeito a formação de sujeitos históricos, críticos e livres. Não finda no processo ensino-aprendizagem ou na mera transmissão de conteúdo (SAVIANI, 2011). Pensar em Educação, principalmente na região amazônica, requer compreender todas as suas particularidades diante da sua extensão territorial, povos e culturas, suas histórias e identidade próprias.

A Ciência pode ser considerada como uma linguagem construída por homens e mulheres para explicar o nosso mundo natural (CHALMERS, 1993). Para que seja integrada na educação básica é necessário trabalhar a formação do professor de ciências com objetivo de lhes manter atualizados das temáticas ciências/tecnologias. Facilitando as práticas na didática dentro da sala de aula e como parte do currículo escolar.

O ensino das Ciências na educação básica tem o compromisso com a educação integral do educando, para que esse possa compreender e interpretar o mundo, permitindo se perceber como parte (BRASIL, 2011). As ciências da natureza devem desenvolver o pensamento crítico, e a habilidade de resolver problemas. Porém, nas ciências vários conceitos requerem abstração, e tornam-se difíceis para os alunos, pois além de abstratos, não são intuitivos. O que acarreta dificuldades para fazer conexões entre os fenômenos físicos com o cotidiano.

Sá (2009) coloca que o nosso modo de pensar sobre a escola e no currículo de ciências são ecos da história impregnada em nós. Nossas escolhas decorrem das demandas da sociedade contemporânea, no sentido de compreender de que modo tais conhecimentos estão presentes na vida dos indivíduos.

No que se refere o papel formativo do professor que trabalhará com a disciplina de Ciências na educação escolar, são muitos os desafios, sobretudo, diante da diversidade amazônica, aonde as discussões educacionais relacionadas a um ensino que contextualize a realidade e suas dinâmicas de aprendizagens ainda nos convida a repensar o modo como estamos abordando o ensino de ciências na região amazônica brasileira. 
Este texto pretende contribuir de forma reflexiva com as discussões acadêmicas sobre a educação em ciências e formação de professores na articulação da teoria e prática para ensinar ciências na região amazônica diante da necessidade de uma educação específica, que atendam as suas singularidades. Para isso, buscou-se fundamentar o texto a partir de pesquisa bibliográfica, estudos e reflexões teóricas, bem como, em debates realizados no âmbito da disciplina "Educação e Realidade Amazônica".

\section{Formação de professores de ciências para atuar na Ama- zônia}

A Formação de professores é um tema bastante discutido na atualidade, e as pesquisas apontam pela necessidade de dar continuidade na investigação dos desafios e impasses com relação à carreira docente. A formação de professores na Amazônia brasileira a partir da perspectiva do ensino de ciências contextualizado e instigador, deve viabilizar o diálogo entre o local e o universal.

Educação na Amazônia implica pensar em uma educação escolar que respeite e reconheça a pluralidade, as singularidades, as especificidades e os conjuntos de elementos culturais do modo de vida do seu povo. Quando não se constroem ou se propõem diálogos que reflitam as reais necessidades da região, está se fazendo uma educação abstrata.

O profissional da educação necessita ter elementos teórico-metodológicos para realizar sua atividade de forma crítica, e construir elementos que subsidiem a epistemologia da práxis, tomando-se o professor como sujeito histórico-social, levando em consideração as relações de poder desde o espaço escolar até o contexto mais amplo, para quem sabe interferir na realidade (CURADO SILVA, 2007).

O ensino de ciências assim como a Amazônia possui suas características e peculiaridades. A compreensão do ensino de ciências no Brasil, a partir da literatura relacionada ao tema, sofreu várias modificações e adaptações, que seguiram o contexto político e social do período em que o país se encontrava. 
Os Parâmetros Curriculares Nacionais de Ciências Naturais (BRASIL, 2001, p. 32) acreditam que a história das Ciências pode contribuir nas relações entre a sociedade humana e a natureza, e essa dimensão histórica pode ser introduzida pelos professores em sala de aula. É imprescindível que o ensino de ciências, na educação básica, aconteça dentro de atividades que os desafiem e permitam a vivência de processos construtivos.

A educação é uma prática social de formação de pessoas, na qual constitui e é constituída de relações sociais, em um contexto contraditório e dialético, podendo manter ou transformar uma realidade (OLIVEIRA, 2019), na qual a realidade é dada materialmente, logo, o indivíduo tem que produzir para sua existência. A educação escolar é uma política pública proposta à constituição da cidadania, aonde a escola é o espaço privilegiado (lócus) de aprendizagem, formação, ensino/trabalho.

Carvalho e Gil Pérez (2003), colocam que os professores de Ciências, na condição de educadores, precisam possuir conhecimento num sentido mais amplo. Entendendo-se que a aprendizagem e saberes da docência têm como fundamento o saber prático. Assim, a prática do professor passa a ser um conjunto de capacidades que permitem resolver os problemas reais do espaço escolar (CURADO SILVA, 2007).

Mas, o que seria a formação docente? Segundo Moreira (2007, p. 109):

Trata-se do desenvolvimento pleno, completo e harmonioso que envolve a aquisição de conhecimentos, atitudes e habilidades, no que se refere em geral e ao processo ensino-aprendizagem que ocorre na escola, nas instituições que se preocupam com o ensino e, especificamente, na sala de aula.

A formação docente deve ser um processo de formação contínua, uma vez que, o professor precisa estar preparado para as mais diversas situações e complexidades da dinâmica de uma sala de aula. E esse processo é resultado de uma reflexão crítica sobre a formação da identidade docente, o "pensar sobre o fazer" (NÓVOA, 1997), os docentes 
tendem resistir a assumir um perfil reflexivo sobre a sua prática, pois é mais fácil deixar como está. Assim:

A formação deve estimular uma perspectiva crítico-reflexiva, que forneça aos professores os meios de um pensamento autônomo e que facilite as dinâmicas de auto-formação participada. Estar em formação implica um investimento pessoal, um trabalho livre e criativo sobre os percursos e os projectos próprios, com vista à construção de uma identidade, que é também uma identidade profissional (NÓVOA, 1997, p. 25)

$\mathrm{Na}$ Amazônia, o ensino de Ciências além dos saberes instituídos nos documentos oficiais que compõem o currículo, deve considerar todas as questões próprias da região, bem como, as temáticas que impactam diretamente vivencia dos alunos e sua comunidade. Santos (2016), alerta para uma abordagem que contextualiza, mas que principalmente contemplem a relação cotidiana e as situações problemáticas dos alunos.

Além desses saberes, os professores que atuarão em um contexto amazônico, possuem um papel fundamental: ajudar as crianças a conhecerem a realidade de nossos ecossistemas, tendo em vista que a Amazônia se constitui numa região rica em biodiversidade e cultura (SANTOS, 2016, p. 8).

O professor de ciências que vier a atuar em um contexto amazônico deverá estabelecer essa relação de saberes, buscando a relação entre os discursos científicos com os discursos locais, viabilizando aos alunos um olhar sobre a Ciência cujos conhecimentos não sejam entendidos como exclusivos dos cientistas/laboratórios carregados de uma perspectiva neutra e desconectados da realidade, mas íntimos e próximos daqueles que historicamente a constroem.

Outro ponto a ser destacado, é a importância de a formação desse profissional ser direcionada seguindo a perspectiva da realidade local. No sentido de existirem alternativas para que esse profissional entenda a necessidade de uma prática pedagógica centrada na vivência dos alunos e seu meio ambiente, bem como, a compreensão profunda da realidade. 
Considerando que a qualidade e a profundidade no domínio dos saberes não são garantidas pela formação acadêmica inicial, mas adquirida com a prática docente em sala de aula, compreendemos que na formação contínua está a possibilidade de apropriação de novos conhecimentos e habilidades.

Silva e Sá (2016, p. 46) assinalam que a formação docente é pouco satisfatória, e em "regiões como a Amazônia, marcada pela diversidade socioespacial, a formação e o processo de ensino-aprendizagem ainda acontecem de forma precária”.

A compreensão do contexto amazônico nos grandes centros urbanos nacionais, ainda consideram, apenas contextos extremos, apresentando como uma região, ou de uma natureza intocada, repleta de fragilidades, ou uma região em processo de desmatamento, devasta e urbanizada (COLARES, 2011). Em um momento inicial, essa compreensão tem se distanciado da perspectiva de uma Amazônia isolada de tudo e todos. Colares e Colares (2019), ressaltam a necessidade de se buscar o reconhecimento dessa diferença, pois é fundamental para uma educação realmente inclusiva e atenta para a diversidade.

Mas precisamos avançar com políticas direcionadas para o desenvolvimento da região e não nos modelos desenvolvidos nacionalmente em outras regiões do país, e sim, dentro de uma perspectiva de modelos adequados para a realidade desse território. Faz-se necessário a realização de estudos sobre todos as problemáticas e, principalmente sobre os programas de formação de professores que possam ultrapassar os limites da cidade e contemplar as várias outras localidades de rios, planaltos e várzeas (SILVA E SÁ, 2016). É imprescindível pensar em educação na Amazônia a partir da Amazônia.

A formação de professores de ciências para atuar no contexto da Amazônia brasileira e as relações que a ciência e seu ensino e aprendizagem tem com a história dessa região estão permeadas de significados que influenciam a formação de professores (VASCONCELOS, 2016). A formação docente é desafio no tange a teoria e a prática quando se objetiva pensar nessa no contexto amazônico. 


\section{Desafios para pensar o ensino de ciências no contexto amazônico}

Compreender as necessidades educacionais do ensino de ciências em qualquer região é desafiador, principalmente, se pensarmos que em cada lugar desse país existem culturas, costumes e modos de vidas diferentes umas das outras. As singularidades dentro dos espaços escolares são profundas, por isso precisa-se desenvolver olhares sobre cada realidade, sem desconsiderar o contexto de diversidade que nesses existem. Outro ponto é não desconsiderar os direitos de aprendizagens que são comuns.

Silva et. al., (2017) abordam que um dos maiores desafios de pensar o ensino ciências é a configuração da sala de aula tradicional, uma vez que, ao estabelecer conexões entre variados pontos dos conteúdos a perspectiva social não pode ser desconsiderada, principalmente, em um país cheio de desigualdade. Uma aula que foge da abordagem tradicional de ensino exige do educador pensar sua prática docente de forma diferenciada, isso no sentido de garantir um ensino que se aproxime da vida cotidiana do aluno.

O ensino de ciências precisa partir da problematização de temas relevantes ao cotidiano do aluno e que envolvam contextos históricos, sociais, econômicos e culturais (BRASIL, 1997). Valores e atitudes não são adquiridos como outros conteúdos do aprendizado (POZO E GÓMEZ CRESPO, 2009).

Seiffert-Santos (2011, p. 216-217), diz que a motivação para ensinar ciências precisa considerar "as pesquisas dentro da própria didática das ciências para não ser gasto energia em pressupostos contestados em pesquisas empíricas, i.e., para direcionar melhor o trabalho docente".

De certo que algumas questões perpassam o lado conceitual de ensinar ciências, tais como: as carências estruturais e as condições de formação e atuação de professores, investimento público e social, políticas voltadas para resultados a longo prazo na melhoria do ensino, não somente de ciências bem como nas outras disciplinas. 
A educação em Ciências na Amazônia precisa ser pensada buscando motivações ligadas a realidade de desenvolvimento da região, voltado à sustentabilidade e em propostas inovadoras contextualizadas para estudante amazônico (SEIFFERT-SANTOS, 2011). Essas motivações devem estarem centradas em um ensino onde o aluno aprende a partir do seu conhecimento prévio, para que ocorra a valorização em relação às atribuições de valores e a observação do contexto sóciocultural. Vale ressaltar que não se desconsidera o processo cognitivo escolar mas

[...] revelará a importância aos valores e saberes prévios. Isso é indispensável quando se pensa em pluralidade cultural, como é o caso do contexto amazônico, um lugar com muitos povos diferentes, com línguas maternas diferentes e de identidade particular. (SEIFFERTSANTOS, 2011, p. 218).

Seiffert-Santos (2011) também comenta sobre haver desmotivadores para o ensino das ciências tanto para o professor como para o aluno. Pozo e Gómez Crespo (2009) afirmam que o ensino de ciências, tradicionalmente, esteve dirigido principalmente a transmitir o corpus conceitual, os principais modelos e teorias geradas pelas ciências para interpretar a natureza e seu funcionamento.

Talvez as práticas pedagógicas adotadas nas aulas de ciências ainda sigam esse modelo de transmissão de informação, sendo essa um reflexo de uma abordagem didática desvinculada da formação científica.

Logo a motivação do estudante será a memorização e não o aprendizado das Ciências para a vida, cotidiano ou alguma prática na sociedade. Precisa-se mudar "a concepção de que ensinar é transmitir informações e técnicas; aprender como memorização e imitação das mesmas" (SEIFFERT-SANTOS, 2011, p. 217).

Existem maneiras e maneiras de ensinar que fogem do tradicional, não que o ensino tradicional não tenha seu valor, pelo contrário, mas é necessário estar atualizado permanentemente, por isso a importância do professor buscar por formações continuadas, uma vez que essa é um elemento base do trabalho docente. 
Um recurso importante para a qualidade do ensino de ciências é a experimentação. A capacitação para tal abordagem deve ser algo prioritário para docentes que venham lecionar ciências. Uma das maiores dificuldades em trabalhar a experimentação nas aulas de ciências está relacionada à um ensino deficiente no que se diz respeito a utilização de metodologias diferenciadas em sala de aula.

No contexto de uma escola no interior da Amazônia, aonde os recursos são ainda mais escassos, caberia ao docente buscar por alternativas mais acessíveis com realidade, como, por exemplo, os materiais alternativos de baixo custo.

Porém, essas questões não são só um desafio docente, não se trata de uma simplificação ou adaptação para as coisas funcionarem conformem as pesquisas colocam metodologicamente bem estruturadas, tratase de universalizar a educação em ciências, pois essa ainda é muito centralizada e não dialogam com as reais necessidades das regiões afastadas dos grandes centros do país. Pois os saberes mudam conforme a sociedade que se está inserido.

A educação em ciências na Amazônia é um desafio para as políticas de governos tanto estaduais como federais, pois são do tamanho da mesma. Para se falar disso, é bom contextualizar sobre a terra das distancias, onde o transporte é difícil, pois a região norte é a terra dos rios (possui a maior bacia fluvial e o maior rio do Brasil), não existem muitas estradas para ligar as cidades, o transporte é fluvial ou aéreo (há lugares que demora-se mais de 15 dias para se chegar de barco, e nessas localidades não há meios de comunicação com os centros urbanos), logo as comunidades tendem a ficar isoladas geograficamente, isso dificultaria o suporte para a Educação (SEIFFERT-SANTOS, 2011, p. 218).

Diante da diversidade, das questões ambientais e dos modelos de desenvolvimento da região, a educação em ciências, precisa ter como eixo principal um ensino capaz de promover a formação de indivíduos críticos, não apenas de conhecimentos técnicos e cientificistas, mas capazes de manter sua visão objetiva dos fenômenos que acontecem em sociedade. 
Para trazer uma abordagem dentro do ensino de ciências que vise as questões mais profundas na Amazônia, é necessário conhecer como os educandos percebem estas questões dentro do seu ambiente em todas as suas dimensões.

E esse processo de conhecimento é fundamental para a compreensão das dificuldades que se colocam entre as grandes problemáticas da Amazônia e suas interfaces com a educação, como, por exemplo: Questões agrarias, territórios e meio ambiente; Biodiversidade; Recursos hídricos e minerais; diversidade cultural; etc.

Seiffert-Santos citando Freitas (2009, p. 219), chama atenção para a necessidade de conhecer a região amazônica, no sentido de compreender "que o paradigma ecológico em um desenvolvimento sustentável é um futuro inevitável tal é a condição do homem no mundo contemporâneo". O ensino de ciência tem potencial para fazer parte desse contexto e pode contribuir com novas formas de ensinar ciências com a cultura local, "sendo tudo isso catalisado com os confrontos 'natureza x cultura', na política nacional e internacional" (SEIFFERT-SANTOS, 2011, p. 219).

No que compreende um currículo escolar na educação básica voltado para as particularidades, especificidades e diversidade que compõem o conjunto de elementos culturais e a educação na Amazônia, o ensino básico nesse contexto, deve expressar as diferenças, as contradições, as etnias, as formas de sobrevivência, construindo um cenário mais diversos que incorpore de fato essas singularidades.

Pensar e fazer a Educação em Ciência para Amazônia, respeitando as necessidades nacionais, e associado ao seu pluralismo é um constante desafio, é assumir a perspectiva de que a "educação não é só ciência, mais saberes", uma vez que, pensar em um currículo homogêneo com uma realidade tão diferenciada, necessita-se de motivação e ação política para se realizar e concretizar.

\section{Considerações finais}

Pensar em Educação na Amazônia não é uma tarefa fácil. É pensar para conhecer. Exige muita reflexão, leitura, pesquisa e estar disposto 
a compreender os atuais processos de mudanças e transformações que a região vem sofrendo e como esses processos têm refletido na própria sociedade. Requer um posicionamento sobre o nosso "lugar de fala", enquanto amazônidas, nos debates sobre a Amazônia.

Atualmente, existem muitas tendências no Ensino de Ciências, mas problematizar temáticas no processo de ensino-aprendizagem no contexto amazônico, requer compreender os "saberes" próprios da região amazônica, saberes que existem da fauna e flora à conhecimento de mitos e lendas que explicam o imaginário.

A partir dessa perspectiva, de reconhecer esses saberes, é propor um currículo contextualizado capaz de contribuir na formação de sujeitos para pensar o seu lugar com respeito e responsabilidade. Mas para essas mudanças comecem é necessário motivação e ação política.

É indiscutível que sem uma educação de qualidade pouco se avança na melhoria do ensino, na construção do conhecimento e nas tomadas de decisões que atendam as reais necessidades do povo da região amazônica.

O desafio docente está em enxergar com mais visibilidade a educação neste cenário, uma vez que para construir propostas pedagógicas que atendam as particularidades de uma escola no interior da Amazônia se faz necessário abarcar também a diversidade e diferentes realidades vivenciadas pelos alunos.

Nesse sentido, conhecer teoricamente as concepções e os processos formativos que articulam com o debate sóciopolitico da educação, contribuem para reflexões acerca da necessidade de se repensar a prática.

Entendemos que é imprescindível que os professores tenham a consciência da importância de sua formação e mais ainda do aperfeiçoamento desta que deverá ser continuado, pois essa é um exercício da compreensão dos desafios que acontecem dentro do ambiente escolar e do exercício profissional.

Saviani (2002, p. 48), coloca que "quanto a nós, se pretendemos ser educadores (especialistas em educação) é porque não nos contentamos com a educação assistemática". Uma vez que, os conhecimentos e os seres humanos seguem em transformação, e acompanhar essa evolu- 
ção remete também ao ensino para que o trabalho docente seja referencia nos campos educacionais.

A Amazônia brasileira não se encontra isolada de tudo, o próprio ambiente nela mudou. Os meios de comunicação (rádio, televisão, internet) trazem notícias sobre acontecimentos num âmbito global. A distância entre ciências e sociedades é inexistente, pois a própria ciência é um produto histórico das interações e ações humanas (SILVA, et. al, 2017).

O desafio de ultrapassar as marcas socialmente e culturalmente estabelecidas pelo sistema escolar nacional representa para o contexto local, que esses conhecimentos fundamentem políticas educacionais e de formação de professores capazes de atender às necessidades e anseios das populações amazônicas. Além dos aspectos discutidos ao longo do texto, dialogar com movimentos sociais, populações locais e os envolvidos no processo de ensino-aprendizagem da educação na Amazônia.

\section{Referências}

ALYRIO, Rovigati Danilo. Métodos e técnicas de pesquisa em administração. Rio de Janeiro: Fundação CECIERJ, 2009.

BRASIL. Ministério da Educação e do Desporto. Secretaria da Educação Fundamental. Parâmetros Curriculares Nacionais: Ciências Naturais. 3. ed. Brasília: A Secretaria, 2001.

S. D. E. F. Parâmetros Curriculares Nacionais: Introdução aos Parâmetros Curriculares Nacionais1, 1997. Brasília. Disponível em: http://portal.mec.gov.br/seb/arquivos/pdf/livro01.pdf Acesso: 23 abr. 2020

CARVAlho, Ana Maria P. de Gil-Pérez, Daniel. Formação de Professores de Ciências: Tendências e Inovações. 7 ed. São Paulo: Cortez Ed., 2003.

CHALMERS, Alan F. O que é Ciências Afinal? Tradução: Raul Filker. Editora Brasiliense, 1993.

COLARES, A. A.; COLARES, M. L. I. S. Diversidade cultural: desafios educacionais no contexto amazônico. Disponível em: $<$ http://www.anpae.org.br/simposio2011/cdrom2011/PDFs/trabalhosCompletos/comunicacoesRelatos/0068.pdf $>$ Acesso em 10 mai. 2020. 
COLARES, A. A. Educação na Amazônia: o papel do gestor na melhoria dos processos educacionais. IN: COLARES, M. L. I. S.; XIMENES-ROCHA, S. H.; COLARES, A. A. Gestão democrática: a escola pública e a formação continuada como objeto de análise. Belém, PA: GTR, 2012.

CURADO SILVA, K. A. P. C. P. A epistemologia da práxis na formação de professores: perspectiva crítico-emancipadora. Revista de Ciências Humanas, v.18, n. 2, 2017. Disponível em: http://revistas.fw.uri.br/index.php/revistadech/article/view/2468 Acesso em 30 jun. 2020.

MOREIRA, Carmem Tereza Velanga. EDUCAÇÃO: Pedagogia, afetividade e emancipação Social. In: MOREIRA, Dorosnil Alves. Ética, Educação, Universidade, Sociedade: reflexões acerca de vivências e práticas como resposta às necessidade sociais no contexto da Amazônia. São Paulo: Expressão popular, 2007.

NÓVOA, António. Formação de Professores e Profissão Docente. In:

NÓVOA, António. Os professores e a sua formação. Dom Quixote: Lisboa, 1997. P. $15-3$

OLIVEIRA, Dayse Kelly Barreiros de. A formação stricto sensu como formação continuada na educação básica: contexto, pressupostos e possibilidades. 2019. 253 f., il. Tese (Doutorado em Educação) — Faculdade de Educação, Universidade de Brasília, Brasília, 2019.Disponível: https://repositorio.unb.br/handle/10482/38314 Acesso em: 04 jul. 2020.

POZO, Juan Ignacio; Crespo, Miguel Àngel Gómez. A aprendizagem e o ensino de ciências: do conhecimento cotidiano ao conhecimento científico. 5. ed. Porto Alegre: Artmed, 2009.

SÁ, Eliane Ferreira de. Discursos de professores sobre ensino de ciências por Investigação. Tese (Doutorado em educação) - Belo Horizonte:

UFMG/FaE, 2009. Disponível em: https://repositorio.ufmg.br/bitstream/ 1843/FAEC-84JQPM/1/2000000177.pdf Acesso em: 04 jul. 2020.

SAVIANI, Dermeval, 1944 - Pedagogia histórico-crítica: primeiras aproximações/Dermeval Saviani11.ed.rev. - Campinas, SP: Autores Associados, 2011. - (Coleção educação contemporânea).

. Educação: do senso comum à consciência filosófica. Autores associados: Campinas, SP, $14^{a}$ ed., 2002. 
SANTOS, Pedro Antonio dos; KIENEN, Nádia; CASTIÑEIRA, Maria Inés. Metodologia da pesquisa social: da proposição de um problema à redação e Apresentação do relatório. São Paulo: Atlas, 2015.

SILVA, Alexandre Fernando da; FERREIRA, José Heleno; VIERA, Carlos Alexandre. $\mathrm{O}$ ensino de ciências no ensino fundamental e médio: reflexões e perspectivas sobre a educação transformadora. Revista Exitus, Santarém/PA, Vol. 7, N² 2, p. 283-304, Maio/Ago 2017. Disponível em: http://www.ufopa.edu.br/portaldeperiodicos/index.php/revistaexitus/article/view/314/262 Acesso em: 4 jul. 2020.

SILVA, Edvalda N. da; SÁ, Wendell R. Desafios da universidade para a formação de professores na Amazônia: uma reflexão sobre a educação do campo. IN: COLARES, A. A.; COLARES, M. L. I. S. (Orgs.) Educação e realidade Amazônica, Vol. I. Campinas/SP: Editora navegando, 2016. Disponível em: <http://www.editoranavegando.com/\#!blank-3/cf0ju > Acesso em 10 mai. 2020.

SEIFFERT-SANTOS, S. C.; TERAN, A. F. Motivadores de Educação em Ciências: um olhar para a Amazônia. In: BARBOSA, I.; TÉRAN, A. F.; GONZAGA, A. M.; NASCIMENTO, M. R. A.; SANTOS, S. C. S.. (Org.). Avanços e Desafios em Processos de Educação em Ciências da Amazônia. 1ed. Manaus: UEA/ Escola Normal Superior / PPGE-ECA, 2011, v. 1, p. 213-224 Disponível em: < https://www.researchgate.net/publication/ 304381612 Avancos e Desafios em Processos de Educacao em Ciencias na Amazonia> Acesso: 22 jul. 2020. 